\title{
Skin Microvascular Reactivity in Children and Adolescents With Type 1 Diabetes in Relation to Levels of Physical Activity and Aerobic Fitness
}

\author{
Denise M. Roche, Sarah Edmunds, Tim Cable, Mo Didi, and \\ Gareth Stratton
}

\begin{abstract}
No studies to date have evaluated the relationship between exercise and microvascular function in youth with type 1 diabetes mellitus (T1DM). Twenty-nine complication free children and adolescents with T1DM were assessed for skin microvascular reactivity, aerobic fitness $\left(\mathrm{VO}_{\text {peak }}\right)$ and physical activity. $\mathrm{VO} 2_{\text {peak }}$ but not physical activity was significantly and independently associated with maximal hyperemia of the skin microcirculation $(p<.01)$. No significant associations were found between venoarteriolar reflex (VAR) vasoconstriction and $\mathrm{VO} 2_{\text {peak }}$ or physical activity. Aerobic fitness may be an important indicator or mediator of effective microvascular endothelial function in youth with T1DM.
\end{abstract}

In children and adolescents with type 1 diabetes mellitus with no clinically overt evidence of microangiopathy, compromised vasodilator and vasoconstrictor responses of the skin microcirculation to a variety of stimuli have been well documented $(18,23,28,29)$. In type 1 diabetes, the compromised integrity of the microand macrocirculation has largely been attributed to endothelial dysfunction $(12,30)$ and this phenomenon is though to antedate clinically detectable microangiopathy (12).

Deferring the appearance and progression of microvascular complications is an ultimate aim in diabetes treatment and research demonstrates this may be achieved through sound glycemic control (11). However, recent evidence suggests that regular exercise can directly enhance endothelial function of the micro- and macrocirculation of adults with chronic diseases such as type 1 diabetes (14), type 2 diabetes (24) and chronic heart failure (16) and animal studies suggest this could be due to vascular shear-stress induced increases in endothelial nitric oxide synthase expression (33). In adults with type 1 diabetes, 4 months of aerobic exercise training sufficient to increase maximal oxygen uptake resulted in systemic

Roche is with the Dept. of Sport and Exercise Science, Liverpool Hope University, Liverpool, L16 9JD, UK. Edmunds is with the School of Human Sciences, St. Mary's University College, Twickenham, TW1 4SX, UK. Cable and Stratton are with the Research Institute for Sport and Exercise Sciences (RISES), Liverpool John Moores University, Liverpool, L2 2ET, UK. Didi is with the Royal Liverpool Children's Hospital, Liverpool, L12 2AP, UK. 
improvements in endothelial function of both conduit and resistance vessels of divergent vascular beds while a period of inactivity reversed these positive adaptations (14). In children, aerobic fitness (36) and habitual physical activity (1) have both been shown to be positively correlated with flow-mediated dilation of the macrocirculation in healthy children and previous endothelial dysfunction of the macrocirculation has partially been reversed in overweight and obese children and adolescents following a period of exercise training $(22,39)$.

Despite such evidence supporting the direct role of exercise in the promotion of vascular health in adults and children and the fact that physical activity continues to be recommended for its health benefits in both children and individuals with type 1 diabetes $(4,32,40)$, no studies to date have examined the relationship between regular exercise and microvascular function in children with type 1 diabetes. This is despite the detrimental and rapid evolution of diabetic microvascular complications $(9,25)$ and consequent need for early intervention strategies. Furthermore, previous research has failed to elucidate exactly what it is about exercise that is beneficial for such vascular health promotion, namely, a high level of fitness or conversely, regular participation in physical activity above a certain intensity. The aim of this study therefore was to evaluate the relationships between aerobic fitness $\left(\mathrm{VO}_{\text {peak }}\right)$ and physical activity with skin microvascular reactivity in children and adolescents with type 1 diabetes.

\section{Methods}

\section{Participants}

Twenty-nine children and adolescents (15 boys and 14 girls; [mean $\pm S D$ ] age $12.5 \pm 2.0$ years), with a minimum duration of type 1 diabetes of 2 years, were recruited from two NHS trusts' diabetes clinics in North West England. Subject characteristics are provided in Table 1. Children and adolescents were free from retinopathy, neuropathy and nephropathy according to normal clinical criteria and had no other illnesses or endocrine disorders other than type 1 diabetes. Participants were taking no medication other than insulin. All participants were treated with multiple subcutaneous insulin injections varying between $2-4$ injections per day. All children and their parent/guardians gave their written, informed assent/ consent to participate in the study which had previously been approved by the Royal Liverpool Children's NHS Trust, the West Lancashire NHS Trust and the Liverpool John Moores University Ethics Committees. All experimental procedures were in accordance with the Declaration of Helsinki.

\section{Anthropometric Measurements}

Adiposity was assessed indirectly from skinfold thicknesses using Harpenden Skinfold Calipers (British Indicators Ltd. Birmingham, England) at 5 sites namely; biceps, triceps, subscapular, suprailiac and medial calf. All measures were obtained on the right side of the body in triplicate and the median value at each site was taken as the accepted value. To minimize the problems associated with the conversion of skinfold values to percentage body fat using equations based on body density, the sum of 5 skinfolds were used to express adiposity (10). Stature was 


\section{Table 1 Subject Characteristics and Study Variables (Values Presented as} Mean $\pm S D$ )

\begin{tabular}{|c|c|c|c|}
\hline & All & Boys & Girls \\
\hline$n$ & 29 & 15 & 14 \\
\hline Maturation ( $n$ per category: pre, pub, post) & $7,15,7$ & $5,7,3$ & $2,8,4$ \\
\hline Age (Years) & $12.5 \pm 2.0$ & $12.3 \pm 1.9$ & $12.7 \pm 2.0$ \\
\hline Stature $(\mathrm{m})$ & $1.52 \pm 0.1$ & $1.52 \pm 0.1$ & $1.51 \pm 0.1$ \\
\hline Mass (kg) & $48.82 \pm 13.9$ & $45.42 \pm 12.9$ & $52.46 \pm 14.4$ \\
\hline $\mathrm{BMI}\left(\mathrm{kg} \cdot \mathrm{m}^{-2}\right)$ & $20.9 \pm 3.9$ & $19.2 \pm 2.4$ & $22.6 \pm 4.5^{*}$ \\
\hline$\Sigma 5 \mathrm{SkF}(\mathrm{mm})$ & $66.2 \pm 32.0$ & $53.6 \pm 16.8$ & $79.7 \pm 38.9 *$ \\
\hline Disease Duration (years) & $6.0 \pm 3.1$ & $6.0 \pm 3.2$ & $6.0 \pm 3.2$ \\
\hline $\mathrm{HbA}_{1 \mathrm{c}}(\%)$ & $9.6 \pm 1.4$ & $9.4 \pm 1.0$ & $9.8 \pm 1.7$ \\
\hline Insulin Dose $\left(\mathrm{U} \cdot \mathrm{kg}^{-1} \cdot \mathrm{d}^{-1}\right)$ & $1.10 \pm 0.20$ & $1.08 \pm 0.19$ & $1.13 \pm 0.22$ \\
\hline Systolic BP (mmHg) & $110.9 \pm 9.8$ & $109.1 \pm 9.7$ & $112.7 \pm 10.1$ \\
\hline Diastolic BP (mmHg) & $68.9 \pm 10.5$ & $66.3 \pm 6.8$ & $71.8 \pm 13.3$ \\
\hline MAP (mmHg) & $82.9 \pm 0.5$ & $80.6 \pm 6.5$ & $79.7 \pm 38.9$ \\
\hline MVPA (minutes $\left.\cdot d^{-1}\right)$ & $46.6 \pm 24.5$ & $57.1 \pm 24.6$ & $35.2 \pm 19.4^{*}$ \\
\hline VPA (minutes $\left.\cdot \mathrm{d}^{-1}\right)$ & $5.8 \pm 6.0$ & $8.9 \pm 6.7$ & $2.6 \pm 2.8 * *$ \\
\hline $\mathrm{VO} 2_{\text {peak }}\left(\mathrm{mL} \cdot \mathrm{kg}^{-1} \cdot \mathrm{min}^{-1}\right)$ & $41.4 \pm 8.2$ & $43.2 \pm 7.3$ & $39.2 \pm 9.0$ \\
\hline SkEF Baseline (PU) & $11.7 \pm 6.7$ & $13.5 \pm 8.5$ & $9.8 \pm 3.4$ \\
\hline SkEF VAR limb dependent (PU) & $5.7 \pm 2.5^{\dagger}$ & $6.0 \pm 3.0^{\dagger}$ & $5.5 \pm 1.9^{\dagger}$ \\
\hline SkEF VAR limb dependent ( $\%$ of baseline) & $54.6 \pm 17.5$ & $52.0 \pm 20.0$ & $57.3 \pm 14.6$ \\
\hline SkEF maximal hyperaemia $42^{\circ} \mathrm{C}(\mathrm{PU})$ & $81.3 \pm 44.1^{\dagger}$ & $80.8 \pm 47.6^{\dagger}$ & $81.8 \pm 41.9^{\dagger}$ \\
\hline $\begin{array}{l}\text { SkEF maximum hyperaemia } 42^{\circ} \mathrm{C}(\% \text { of } \\
\text { baseline) }\end{array}$ & $769.7 \pm 384.4$ & $686.9 \pm 295.4$ & $858.5 \pm 455.8$ \\
\hline
\end{tabular}

Note. BMI, body mass index; $\Sigma 5 \mathrm{SkF}$, sum of 5 skinfolds; $\mathrm{HbA}_{1 \mathrm{c}}$, glycosylated hemoglobin; $\mathrm{BP}$, blood pressure; MVPA, moderate-to-vigorous physical activity; VPA, vigorous physical activity; SkEF, skin erythrocyte flux; VAR, venoarteriolar reflex.

$* p<0.05 * * p<0.01$ significantly different from boys.

${ }^{\dagger} p<.001$ significantly different from baseline skin blood flow.

measured to the nearest $0.25 \mathrm{~cm}$ using a wall-mounted stadiometer (British Indicators Ltd. Birmingham, England) and body mass to the nearest $0.10 \mathrm{~kg}$ using beam balance scales (Avery, Birmingham, England) with subjects wearing light clothing, shoes removed. Body mass index (BMI) was calculated as BMI = mass $(\mathrm{kg}) /$ stature $^{2}\left(\mathrm{~m}^{2}\right)$.

\section{Protocol for the Assessment of Skin Erythrocyte Flux (Maximum Hyperemia and Venoarteriolar Reflex)}

Skin blood flow assessment is a noninvasive technique that has been widely used to gain insights into the health status of the skin microcirculation and the detection of subclinical diabetic microangiopathy (27). Microvascular function and abnor- 
malities of vascular endothelial, smooth muscle or neurogenic origin can be detected through laser Doppler flowmetry by challenging the microcirculation through, for example, local heating or limb dependency.

All skin blood flow tests were conducted in a temperature-controlled environment $\left(22-24.5^{\circ} \mathrm{C}\right)$ approximately $2-3 \mathrm{hr}$ after children had a light meal and their usual insulin (23). Participants were requested to refrain from physical activity or caffeine ingestion before skin blood flow evaluation. All participants were in normoglycaemia during the assessment of skin blood flow. Participants were lightly clothed and allowed a 20 min equilibration period in the supine position before skin erythrocyte flux (SkEF) assessment commenced. Skin temperature was continuously measured throughout testing using a thermostatic probe holder (Peritemp PF 450, Perimed, Järfälla, Sweden). Skin erythrocyte flux (SkEF) was noninvasively assessed on the lateral aspect of the lower leg, $10 \mathrm{~cm}$ proximal to the lateral malleolus, using a laser Doppler (Periflux System 4001, Perimed, Järfälla, Sweden). This technique has been described in detail elsewhere (27). Briefly, the laser Doppler technique for the analysis of tissue perfusion involves the illumination of an area of skin $\left(0.5 \mathrm{~mm}^{2}\right)$ to a depth of $0.5-1.0 \mathrm{~mm}$ with a beam of monochromatic light from a fiber-optic probe adhered to the skin. The laser Doppler operates on the Doppler principle whereby laser light penetrating skin tissue is scattered by moving red blood cells and undergoes a change in frequency (Doppler shift). The magnitude of the Doppler frequency shift is recorded by photodetecters in the fiber-optic head of the laser probe and converted to an output signal termed 'skin erythrocyte flux' which is a product of the velocity and concentration of moving red blood cells. It is expressed in arbitrary perfusion units (PU) or millivolts $(1 \mathrm{PU}=10 \mathrm{mV})$.

Baseline SkEF was recorded with participants assuming a supine position, with both limbs rested at heart level until clear, stable flow records were obtained (this took approximately $10 \mathrm{~min}$ ). The integrity of the venoarteriolar reflex (VAR) was assessed by monitoring SkEF after the foot was passively lowered to the vertical position, approximately $30 \mathrm{~cm}$ below heart level for $4 \mathrm{~min}(17,38)$. SkEF in the dependent position was calculated as the mean SkEF during the last minute of limb dependency. The vasoconstrictor integrity of the VAR was calculated as SkEF during dependency/baseline SkEF $\times 100$ (29). Maximal hyperaemia of the skin microcirculation was induced by locally heating a small area of skin to $42{ }^{\circ} \mathrm{C}$ (35) using a standard heater (Perimed, Järfälla, Sweden). The maximum hyperemic response during thermal provocation was measured as the maximum SkEF recorded for 1 continuous minute (PU), once the thermal plateau had been attained (typically reached between 10 and $20 \mathrm{~min}$ ). For all skin blood flow measures, the Doppler signal, expressed in arbitrary perfusion units (PU), was recorded onto a PC using Biopac Software (Biopac Systems Software Inc. Santa Barbara, CA). To reduce noise and movement artifacts, the Doppler signal was filtered using a low band pass filter before analysis.

\section{Determination of $\mathrm{VO2}_{\text {peak }}$}

Peak oxygen uptake was assessed with a discontinuous, incremental treadmill run to voluntary exhaustion. The treadmill protocol consisted of $3 \mathrm{~min}$ stages of constant velocity running beginning at zero gradient and increasing by $2.5 \%$ at the 
end of each three minute work-stage. Treadmill test velocity was between 7 and $12 \mathrm{~km} \cdot \mathrm{hr}^{-1}\left(9.0 \pm 1.5 \mathrm{~km} \cdot \mathrm{hr}^{-1}\right)$ and was determined according to age, maturation and competence during warm-up/familiarization. Expired air was collected in meteorological (MET) balloons (Cranlea Medical Electronic, Birmingham, England) during the final $30 \mathrm{~s}$ of each workstage and the final $30 \mathrm{~s}$ of the test for determination of expired oxygen and carbon dioxide concentrations and total volumes using precalibrated dry-gas analysers (Servomex 470A and 1400, Servomex, Crowborough, England; Harvard Dry Gas Meter, Harvard Apparatus, Edenbridge, England respectively). Oxygen uptake for each MET balloon was calculated on a $\mathrm{PC}$ using the Haldane transformation calculations. Heart rate was measured at $5 \mathrm{~s}$ intervals throughout the test protocol using short range radio telemetry (Polar Sports Tester, Kempele, Finland). BASES (1997) guidelines (6) were adhered to for test end point criteria for $\mathrm{VO} 2_{\text {peak }}$ determination namely: subjective fatigue and volitional exhaustion, a final heart rate within 10 beats $\cdot \mathrm{min}^{-1}$ of the age-predicted maximum (220-age), a final RER of 1.15 or above. If satisfactory test end-point criteria were not met, subjects' $\mathrm{VO} 2_{\text {peak }}$ data were excluded from the analysis.

\section{Estimation of Physical Activity}

Physical activity was estimated using continuous heart rate monitoring (Polar Sports Tester, Kempele, Finland; 37) on two week days and two days and one night at the weekend. The heart rate monitors were set to record heart rates every $60 \mathrm{~s}$. Heart rate files of $\geq 8 \mathrm{hr}$ in duration were downloaded using an interface onto a PC for analysis using Polar Precision Performance Software 3.0. (Polar, Kempele, Finland) after being edited to omit periods of radio telemetry interference, zero heart rates from loss of skin contact or supra-physiological heart rates from random artifacts. A series of HR thresholds based on the heart rate reserve (HRR) method (20) were used to establish levels of physical activity. For the HRR calculation (HRmax-HRrest), maximum heart rate was that value at the end of the $\mathrm{VO} 2_{\text {peak }}$ test, and the resting heart rate was an average of the lowest 5 consecutive heart rates during sleep. A number of different methods have previously been employed to analyze heart rate data for the determination of children's levels of physical activity (13). The preferred method used in this study, and employed elsewhere $(13,31)$, involved the determination of two thresholds: $\geq 50 \% \mathrm{HRR}$ and $\geq 75 \%$ HRR which have been previously used in the literature as corresponding to moderate-to-vigorous (MVPA) and vigorous physical activity (VPA) respectively (31). The threshold 50\%HRR is considered to represent the lower limit for aerobic fitness effects (13). The total accumulated time (in minutes) spent per day at each intensity of HRR was used to establish levels of MVPA and VPA for each individual.

There were some instances where there was a loss of electrode contact with the skin or transmitter interference which meant that complete heart rate monitoring data sets were not available for all participants. Heart rate files were included in the physical activity analysis if they were of a duration of $8 \mathrm{hr}$ or longer. Using this criteria $52 \%$ of children had complete data sets, $24 \%$ had 3 complete files, $17 \%$ had 2 complete files and $7 \%$ had 1 complete file. All 100\% of participants had at least 1 week-day recording and of these, a total of $86 \%$ of children also had at least 1 weekend day and an overnight data file. Analysis of variance revealed there were no significant differences between levels of weekday and weekend 
physical activity. Given this, physical activity at the two intensities was expressed in minutes per day and was the average number of minutes of physical activity across the corresponding number of recording days. All participants with one or more data files were included.

\section{Glycemic Control}

Participants glycosylated hemoglobin values $\left(\mathrm{HbA}_{1 \mathrm{c}}\right)$ were determined to the nearest $0.1 \%$ via latex immuno-agglutination inhibition techniques (Bayer DCA 2000, Bayer Diagnostics, Newbury, Berkshire, UK) during routine clinical assessment. The $\mathrm{HbA}_{1 \mathrm{c}}$ values were taken within 6 weeks of both the laboratory visit and assessment of physical activity. Normal laboratory values for patients without diabetes are between 2.0 and $6.5 \%$.

\section{Maturation}

Pubertal status was determined by a consultant pediatric endocrinologist as part of the child's routine medical care. Pubertal status was made using Tanner's classification (34).

\section{Data Analysis}

Statistical analysis was performed using SPSS for Windows (Version 15.0). Normality was tested using the Kolmogorov-Smirnov test. Both maximal hyperemia and VPA data were skewed and therefore were log transformed to conform to normality assumptions. Sex differences in physiological characteristics, physical activity, $\mathrm{VO} 2_{\text {peak }}$ and $\mathrm{SkEF}$ were assessed using $t$ tests for independent samples. Relationships between $\mathrm{VO} 2_{\text {peak }}$ or physical activity on the one hand and maximal hyperemia or VAR-vasoconstriction of the skin microcirculation were assessed using Pearson's Product Moment Correlation Coefficient. Forward multiple regression analysis was employed to determine the independent contribution made by $\mathrm{VO} 2_{\text {peak }}$ to maximal hyperemic response while controlling for age, adiposity, $\mathrm{HbA}_{1 \mathrm{c}}$ and gender. Statistical significance was set at $p<.05$ throughout. Means $\pm S D$ are reported.

\section{Results}

There were no differences between boys and girls for glycaemic control, age, disease duration, stature, mass, insulin use, systolic/diastolic blood pressure, or microvascular responses (Table 1). The girls had a significantly higher sum of 5 skinfolds compared with the boys (mean $\pm S D$; $\Sigma 5 \mathrm{SkF}$ : girls $79.7 \pm 38.9$; boys: $53.6 \pm 16.8 \mathrm{~mm}, p=.03$ ). In addition, BMI was significantly higher in the girls compared with the boys (girls: $22.6 \pm 4.5$; boys: $19.2 \pm 2.4 \mathrm{~kg} \cdot \mathrm{m}^{-2}, p=.02$ ).

\section{Physical Activity, $\mathrm{VO}_{\text {peak }}$ and Glycemic Control}

As seen in Table 1, mean MVPA accumulated daily by participants was $46.6 \pm$ $24.5 \mathrm{~min} \cdot \mathrm{d}^{-1}$, and was significantly higher in the boys $\left(57.1 \pm 24.6 \mathrm{~min} \cdot \mathrm{d}^{-1}\right) \mathrm{com}$ pared with the girls $\left(35.2 \pm 19.4\right.$ min. $\left.^{-1}\right),(p<.013)$. Total daily cumulative time 
for participants spent performing VPA was $5.6 \pm 6.0 \mathrm{~min} \cdot \mathrm{d}^{-1}$ for the whole group, with higher levels displayed by the boys $\left(8.9 \pm 6.7 \mathrm{~min} \cdot \mathrm{d}^{-1}\right)$ compared with the girls $\left(2.6 \pm 2.8 \mathrm{~min} \cdot \mathrm{d}^{-1} ; p=.004\right)$. Thirty-one percent of participants accumulated at least $60 \mathrm{~min}$ of MVPA per day (2 (14\%) girls and 7 (47\%) boys) and $72 \%$ accumulated at least 30 min of MVPA per day.

The results from the maximal treadmill test are also displayed in Table 1. Two girls failed to attain acceptable true $\mathrm{VO} 2_{\text {peak }}$ values based on test end-point criteria, and were therefore excluded from all subsequent analyses involving $\mathrm{VO} 2_{\text {peak }}$. $\mathrm{VO} 2_{\text {peak }}$ for all subjects $(n=27)$ was $41.4 \pm 8.2 \mathrm{~mL} \cdot \mathrm{kg}^{-1} \cdot \mathrm{min}^{-1}$ and was not significantly different for boys $\left(43.2 \pm 7.3 \mathrm{~mL} \cdot \mathrm{kg}^{-1} \cdot \mathrm{min}^{-1}\right)$ and girls $(39.2 \pm 9.0$ $\left.\mathrm{mL} \cdot \mathrm{kg}^{-1} \cdot \mathrm{min}^{-1}\right)$.

No relationship was evident between glycaemic control and aerobic fitness whether all subjects were considered as one group $(r=.12, p=.57)$ or separately by sex (boys: $r=-.15, p=.60$; girls: $r=.40, p=.20$ ). Likewise, no significant associations were found between $\mathrm{HbA}_{1 \mathrm{c}}$ and physical activity (MVPA whole group: $r=-.05, p=.79$; boys: $r=-0.12, p=.68$; girls $r=.11, p=.71$; VPA whole group: $r=-.39, p=.06$; boys: $r=.35, p=.25$; girls: $r=-.49, p=.09$ ).

\section{Peak VO2 and Skin Microvascular Reactivity}

In univariate analysis, considering the group as a whole, there was a significant correlation between $\mathrm{VO} 2_{\text {peak }}$ expressed relative to body mass $\left(\mathrm{mL} \cdot \mathrm{kg}^{-1} \cdot \mathrm{min}^{-1}\right)$ and maximal hyperaemia during local $42{ }^{\circ} \mathrm{C}$ heating $(r=.54, p=.005$; Figure 1$)$. This correlation remained significant when the relationship was reassessed using separate groups for boys and girls (boys: $r=.58, p=.04$; girls: $r=.54, p=.04$ ). There was no significant correlation between $\mathrm{VO} 2_{\text {peak }}\left(\mathrm{mL} \cdot \mathrm{kg}^{-1} \cdot \mathrm{min}^{-1}\right)$ and SkEF during limb dependency (VAR) expressed relative to baseline SkEF for the whole group $(r=.06, p=.77)$ or in the sex-specific analyses (boys: $r=-.07, p=.79$; girls: $r=$ $.34, p=.28)$.

To determine whether $\mathrm{VO} 2_{\text {peak }}$ made an independent contribution to the maximal hyperaemic response of the skin microcirculation, a multiple regression analysis was performed on the whole group with $\mathrm{VO} 2_{\text {peak }}$ entering the model first, followed by adiposity ( 25 skinfolds), age, gender and $\mathrm{HbA}_{1 \mathrm{c}} \cdot \mathrm{VO} 2_{\text {peak }}$ expressed relative to body mass remained a significant independent predictor of maximal hyperaemia during local $42{ }^{\circ} \mathrm{C}$ heating (model $R^{2}=.29, p=.005$ ). No other variables made a significant, independent contribution to maximal hyperaemia as seen in Table 2.

\section{Physical Activity and Skin Microvascular Reactivity}

Maximal hyperaemia was not significantly correlated with daily accumulated time spent performing physical activity of either intensity when whole group or sex-specific analyses were performed (MVPA whole group: $r=.12, p=.54$; boys: $r=.20, p=.47$; girls $r=.04, p=.88$; VPA whole group: $r=-.15, p=.49$; boys: $r=-.41, p=.18$; girls: $r=-.14, p=.66)$. Likewise, SkEF during limb dependency expressed relative to baseline SkEF (VAR) was not correlated with physical activity of either intensity in whole group or sex-specific analyses (MVPA whole group: $r=.006, p=.97$; boys: $r=.27, p=.33$; girls: $r=-0.25, p=.39$; VPA whole group $r=-.01, p=.96$; boys: $r=-.17, p=.56$; girls: $r=.02, p=.94$ ). There were 


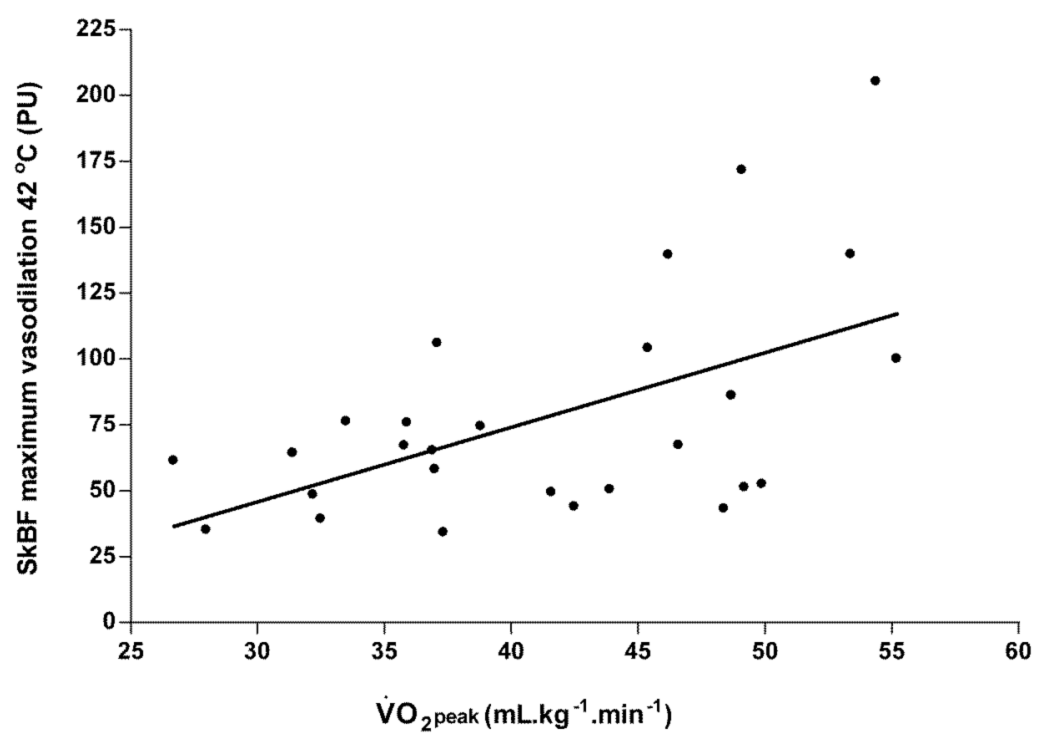

Figure 1 - Relationship between maximal SkEF of the skin microcirculation in the lower leg in response to local $42^{\circ} \mathrm{C}$ heating and $\mathrm{VO} 2_{\text {peak }}(r=.54, p<.01)$.

Table 2 Summary of the Multiple Regression Analysis for (Ln) Maximal Hyperaemia in the Lower Leg During Local Heating (PU)

\begin{tabular}{lcc}
\hline & \multicolumn{2}{c}{ SkEF Maximal Hyperemia at $\mathbf{4 2}^{\circ} \mathbf{C}(\mathbf{P U})$} \\
\hline & $\beta$ & $\boldsymbol{p}$ \\
\hline $\mathrm{VO} 2_{\text {peak }}$ & 0.54 & .005 \\
Gender & 0.06 & 0.76 \\
Age & -0.22 & 0.21 \\
25 Skinfolds & -0.13 & 0.56 \\
$\mathrm{HbA}_{1 \mathrm{c}}$ & -0.28 & 0.11 \\
\hline
\end{tabular}

$\beta$ represents the standardized beta coefficients from the regression equation (model $R^{2}=.29, p=$ $.005)$.

no correlations evident between maximal hyperemia or VAR-vasoconstriction and either the duration of diabetes or glycaemic control.

\section{Discussion}

This is, to our knowledge, the first study in which the relationship between skin microvascular function and chronic exercise has been examined in childhood type 1 diabetes. The main finding of our study was that aerobic fitness but not physical activity of at least moderate-to-vigorous intensity was positively associated with maximal hyperaemia as measured by locally heating to $42{ }^{\circ} \mathrm{C}$, the skin's microcir- 
culation. In contrast, we determined that the VAR-vasoconstrictor responses of the skin microcirculation did not appear to be associated with either aerobic fitness or physical activity. These findings were the same whether whole group or sex-specific analyses were performed.

Our finding of a moderately strong relationship between aerobic fitness and maximal hyperemia of the skin microcirculation in type 1 diabetic children and adolescents is consistent with previous findings involving adults with type 1 diabetes (14). Fuchsjäger-Mayrl and colleagues $(2002 ; 14)$ reported a significant and positive correlation between $\mathrm{VO} 2_{\max }$ (aerobic fitness) and endothelial responsiveness of the ocular resistance vessels in type 1 diabetic adults following exercise training. Significant correlations between aerobic fitness and both the maximal hyperemic response to local heating and the peak ACh response (endotheliumdependent) of the skin microcirculation of the dorsal aspect of the foot in healthy adults at risk for developing type 2 diabetes have also been shown (26). Our results and those of others $(14,26)$ suggest that higher levels of aerobic fitness may be commensurate with superior skin microvascular vasodilatory capacity, and hypothetically therefore that the development of skin microvascular dysfunction may be attenuated or delayed by improving aerobic fitness. It has in fact been successfully demonstrated that the maximal vasodilatory capacity of conduit vessels significantly improves when aerobic fitness is augmented following a period of exercise training in obese adolescents (39) and adults with chronic heart failure and type 2 diabetes $(16,24)$.

We could not determine the site or mechanism for the association between aerobic fitness and the vasodilatory capacity of the skin microcirculation in the current study as this would require further, more demanding physiological tests such as iontophoresis or microdialysis. However, local heating to $42{ }^{\circ} \mathrm{C}$, as was used in this study, causes maximal cutaneous vasodilation which, in addition to local neurogenic mechanisms, is heavily dependent on nitric oxide (NO;21). NO is compromised in type 1 diabetes due to hyperglycemia-induced oxidative stress increases in NO degradation and NO quenching $(8,30)$. In the current study, when an area of skin on the lower leg was heated to $42{ }^{\circ} \mathrm{C}$, the maximal hyperaemic response equated to a sevenfold increase from baseline flow, a considerably lower increase than reported by Khan et al. $(2000 ; 23)$ at the dorsum of the foot of 18.4 v's 25.5 for patients with type 1 diabetes (aged 9-22, mean duration 6.6 years) versus healthy. The current participants had a mean age of 12.5 years and a disease duration of 6 years (range 2.5-13 years). Maximum hyperemic responses to local heating correlate inversely with disease duration (28). Therefore comparing the maximal hyperemic values in this study to other studies in which participants had similar disease durations, using either the ratio or absolute method to express maximal hyperemia, the current participants appeared to display attenuated NOdependent responses to thermal provocation $(23,28)$. It is notable therefore that NO-dependent maximal hyperemic responses were superior in participants in the current investigation with higher levels of aerobic fitness.

In the current study, multiple-regression analysis revealed that aerobic fitness was the only independent predictor, of those considered (age, adiposity, gender and $\mathrm{HbA}_{1 \mathrm{c}}$ ), of maximal hyperemia of the skin microcirculation which was somewhat surprising given the established role of chronic hyperglycemia in microvascular dysfunction in type 1 diabetes (7). However, other researchers have also recently attested to the existence of an independent effect of exercise on conduit vessel 
health in children (22). Furthermore, contemporary exercise training studies in adults with type 1 and 2 diabetes and chronic heart failure have determined that the mechanism by which chronic exercise causes enhanced micro- and macrovascular function is through altered endothelial function $(14,16,24)$, and likely involves exercise-induced elevations in vascular shear-stress which subsequently increases the bioavailability of NO synthase (33). Furthermore, previous research describes a significant association between resting plasma nitrate concentration, an index of basal NO formation, and physical fitness (19). We therefore hypothesize that the association between aerobic fitness and maximal hyperemia of the skin microcirculation in the current study likely involves the endothelium and the nitric oxide system although vascular smooth muscle adaptations might also play a part.

According to current US and UK physical activity guidelines $(4,32), 31 \%$ of the children and adolescents with diabetes in our study (14\% girls, $47 \%$ boys) accumulated $60 \mathrm{~min} \cdot \mathrm{d}^{-1}$ of activity at an intensity sufficient to promote cardiorespiratory fitness (greater than $50 \% \mathrm{HRR}$ ), while $72 \%$ accumulated $30 \mathrm{~min} \cdot \mathrm{d}^{-1}$ above this threshold. A wide range of physical activity levels were also displayed by the participants ranging from 10.5 to $92 \mathrm{~min} \cdot \mathrm{d}^{-1}$ in the boys and 11.0 to $74.6 \mathrm{~min} \cdot \mathrm{d}^{-1}$ in the girls. Although estimation of physical activity is inherently difficult and interpretation of findings depends upon operational definitions, we are confident that through using the valid method of heart rate monitoring (37) and the method of HRR to calculate specific intensity thresholds (20), the lack of association between physical activity and skin microvascular reactivity in this study was unlikely to be due to methodological limitations or a narrow range of participants' physical activity.

One explanation for the lack of association with skin microvascular reactivity and physical activity in the current study could be due to the fact that a number of study participants were pubertal which is a time of instability in glycaemic control in patients with type 1 diabetes. Puberty-related fluctuations in $\mathrm{HbA}_{1 \mathrm{c}}$ could possibly contribute to short-term alterations in microvascular function which would render the impact of physical activity on vascular status and metabolic control inconsequential. However, we did not find any significant differences in glycemic control and either maximal hyperaemia of the skin microcirculation or the integrity of the VAR in our pubertal subjects compared with their pre- and postpubertal counterparts (unpublished observations). Therefore instead, we propose that the volume, type and manner in which physical activity is performed by our diabetic patients may not be conducive to impacting on vascular status. Goto and colleagues (15) have previously reported that endothelium-dependent vasodilatory capacity augmentation is dependent on the intensity of exercise training. We therefore propose that the accumulation of unplanned, short $(<5 \mathrm{~min})$, sporadic bouts of moderate intensity aerobic activity, as displayed by our participants and typical generally of youth (3), may not have been a sufficient stimulus to have a tenable and immediate impact on micro- and macrovascular integrity. Indeed, in this study, there was no association between aerobic fitness and daily levels of MVPA or VPA. While not unanimously supported, a lack of association between children's cardiorespiratory fitness and levels of physical activity has been alluded to elsewhere (2) and it has been proposed that children's physical activity levels and patterns do not stress the aerobic system sufficiently to improve $\mathrm{VO} 2$ peak.

In the current study, no association was found between VAR-vasoconstriction and either aerobic fitness or physical activity and there are no studies with which to compare our findings. The VAR involves local sympathetic axon reflexes in part 
mediated by local myogenic mechanisms with some central contribution (17) and a compromised VAR could arise from pathophysiological changes such as attenuated production of vasoactive substances or basement membrane thickening (30). An intact VAR is important as an increase in vascular resistance on standing for example prevents orthostatic hypertension and excessive rises in capillary pressure. In this regard, the lack of association between the VAR and both aerobic fitness and physical activity in the current study was novel finding. Given the complexity of factors contributing to the VAR and the possibility that structural and functional adaptations of these contributors to chronic exercise may be timedependent, we propose that associations between aerobic fitness or physical activity and VAR vasoconstriction may only be detectable in older patients with some degree of autonomic failure or a longer history of chronic exercise.

There were some limitations to this research, most notably that the relatively small sample size could have had an impact on findings and their generalizability. A further limitation was that the study design was cross-sectional in nature and there was no nondiabetic control group. We therefore cannot infer causality or determine whether our findings are exclusive to children with the chronic disease type 1 diabetes with similar physiological and metabolic profiles to our own. At present therefore, it is not possible to discern the direction of the relationship between microvascular function and fitness so we cannot categorically state whether in this study aerobic fitness acts an indicator or a mediator of effective microvascular endothelial function. It is well-established that the positive benefits of an active lifestyle and sound aerobic fitness during childhood and through the teenage years may not be immediate, but rather they impact on adult health. In fact, this remains one of the fundamental premises on which physical activity promotion in youth is based (5). A longitudinal study would therefore be the most suitable means for further assessing the efficacy of chronic exercise on vascular health in patients with type 1 diabetes.

In conclusion, we have demonstrated that vasodilatory responses of the skin microcirculation, which are heavily dependent on NO, are superior in fitter children and adolescents with type 1 diabetes but not necessarily the more active ones. Exercise remains a cornerstone in the treatment of type 1 diabetes and the lucid determination of its full remedial capabilities, from childhood to adulthood, in this chronic disease deserves further investigation. Larger-scale empirical research should now explore the potential therapeutic roles of both physical activity and fitness in children with type 1 diabetes so that optimal exercise prescription guidelines for diabetes management and the prevention of complications may be discerned.

\section{Acknowledgments}

This work has previously been presented at the Annual Conference of the British Association of Sport and Exercise Scientists, Liverpool, UK, September 2004 and appears in abstract form in the Journal of Sports Sciences 23:A160, 2005.

\section{References}

1. Abbott, R.A., M.A. Harkness, and P.S.W. Davies. Correlation of habitual physical activity levels with flow-mediated dilation of the brachial artery in 5-10 year old children. Atherosclerosis. 160:233-239, 2002. 
2. Armstrong, N., J. Balding, P. Gentle, J. Williams, and B. Kirby. Peak oxygen uptake and habitual physical activity in 11 to 16 year olds. Pediatr. Exerc. Sci. 2:349-358, 1990.

3. Armstrong, N., and S. Bray. Physical activity patterns defined by continuous heart rate monitoring. Arch. Dis. Child. 66:245-247, 1991.

4. Biddle, S., N. Cavill, and J. Sallis. Policy framework for young people and healthenhancing physical activity. In: Young and Active? Young people and health enhancing physical activity: Evidence and implications, S. Biddle, N. Cavill, and J. Sallis (Eds.). London: Health Education Authority, 1998, pp. 3-16.

5. Boreham, C., and C. Riddoch. The physical activity, fitness and health of children. $J$ Sports Sci. 19:915-929, 2001.

6. British Association of Sport and Exercise Sciences. Bird, S. and R. Davison. (Eds). Guidelines for the Physiological Testing of Athletes. Leeds, British Association of Sport and Exercise Sciences, 1997.

7. Brownlee, M. Biochemistry and molecular cell biology of diabetic complications. Nature. 414:813-820, 2001.

8. Bucala, R., K.J. Tracey, and A. Cerami. Advanced glycosylation products quench nitric oxide and mediate defective endothelium-dependent vasodilation in experimental diabetes. J. Clin. Invest. 87:432-438, 1991.

9. Cheung, A.T.W., A.R. Price, P.L. Duong, et al. Microvascular abnormalities in pediatric diabetic patients. Microvasc. Res. 63:252-258, 2002.

10. Claessens, A.L., G. Beunen, and R.M. Malina. Anthropometry, physique, body composition and maturity. In: Paediatric Exercise Science and Medicine, N. Armstrong and W. Van Machelen (Eds.). Oxford: Oxford University Press, 2000, pp. 11-22.

11. DCCT Research Group. The Diabetes Control and Complications Trial Research Group. The effect of intensive treatment of diabetes on the development and progression of long-term complications in insulin-dependent diabetes mellitus. N. Engl. J. Med. 329:977-986, 1993.

12. Dogra, G., L. Rich, K. Stanton, and G.F. Watts. Endothelium-dependent and independent vasodilation studied at normoglycaemia in type I diabetes mellitus with and without microalbuminuria. Diabetologia. 44:593-601, 2001.

13. Epstein, L.H., R.A. Paluch, L.E. Kalakanis, G.S. Goldfield, F.J. Cerny, and J.N. Roemmich. How much activity do youth get? A quantitative review of heart-rate measured activity. Pediatrics. 108:E44, 2001.

14. Fuchsjäger-Mayrl, G., J. Pleiner, G.F. Wiesinger, et al. Exercise training improves vascular endothelial function in patients with type 1 diabetes. Diabetes Care. 25:1795-1801, 2002.

15. Goto, C., Y. Higashi, M. Kimura, et al. Effect of different intensities of exercise on endothelium-dependent vasodilation in humans. Role of endothelium-dependent nitric oxide and oxidative stress. Circulation. 108:530-535, 2003.

16. Hambrecht, R., E. Fiehn, C. Weigl, et al. Regular physical exercise corrects endothelial dysfunction and improves exercise capacity in patients with chronic heart failure. Circulation. 98:2709-2715, 1998.

17. Hassan, A.A.K., and J.E. Tooke. Mechanism of the postural vasoconstrictor response in the human foot. Clin. Sci. 75:379-387, 1998.

18. Hu, J., M. Norman, M. Wallensteen, and G. Gennser. Dynamic properties of the aorta and of the foot microcirculation in adolescents with diabetes mellitus. Acta Paediatr. 86:620-625, 1997.

19. Jungersten, L., A. Ambring, B. Wall, and A. Wennmalm. Both physical fitness and acute exercise regulate nitric oxide formation in healthy humans. J. Appl. Physiol. 82:760-764, 1997.

20. Karvonen, M.J., E. Kentala, and O. Mustala. The effects of training on heart rate; a longitudinal study. Ann. Med. Exp. Biol. Fenn. 35:307-315, 1957. 
21. Kellogg, D.L., Y. Liu, I.F. Kosiba, and D. O'Donnell. Role of nitric oxide in the vascular effects of local warming of the skin in humans. J. Appl. Physiol. 86:1185-1190, 1999.

22. Kelly, A.S., R.J. Wetzsteon, D.R. Kaiser, J. Steinberger, A.J. Bank, and D.R. Dengel. Inflammation, insulin and endothelial function in overweight children and adolescents: the role of exercise. J. Pediatr. 145:731-736, 2004.

23. Khan, F., T.A. Eldhadd, S.A. Greene, and J.J.F. Belch. Impaired skin microvascular function in children, adolescents and young adults with type I diabetes. Diabetes Care. 23:215-220, 2000.

24. Maiorana, A., G. O'Driscoll, C. Cheetham, et al. The effect of combined aerobic and resistance exercise training on vascular function in type 2 diabetes. J. Am. Coll. Cardiol. 38:860-866, 2001.

25. Malone, J.I., A.D. Morrison, P.R. Pavan, and D.D. Cuthbertson. Prevalence and significance of retinopathy in subjects with type 1 diabetes of less than 5 years' duration screened for the Diabetes Control and Complications Trial. Diabetes Care. 24:522-526, 2001.

26. Middlebrooke. A.R., N. Armstrong, J.R. Welsman, A.C. Shore, P. Clark and K.M. MacLeod. Does aerobic fitness influence microvascular function in healthy adults at risk of developing type 2 diabetes? Diabet. Med. 22:483-489, 2005.

27. Rendell, M., T. Bergman, G. O'Donnell, E. Drobny, J. Borgos, and R.F. Bonner. Microvascular blood flow, volume and velocity measured by laser Doppler techniques in insulin dependent diabetes. Diabetes. 38:819-824, 1989.

28. Shore. A.C., K.J. Price, D.D. Sandeman, E.M. Green, J.H. Tripp and J.E. Tooke. Impaired microvascular hyperaemic response in children with diabetes mellitus. Diabet. Med. 8:619-623, 1991.

29. Shore. A.C., K.J. Price, D.D. Sandeman, J.H. Tripp and J.E. Tooke. Posturally induced vasoconstriction in diabetes mellitus. Arch. Dis. Child. 70:22-26, 1994.

30. Stehouwer, C.D.A., J. Lambert, A.J.M. Donker, and V.W.M. van Hinsbergh. Endothelial dysfunction and pathogenesis of diabetic angiopathy. Cardiovasc. Res. 34:55-68, 1997.

31. Stratton, G. Children's heart rates during physical education lessons: a review. Pediatr. Exerc. Sci. 8:215-233, 1996.

32. Strong, W.B., R.M. Malina, C.J. Blimkie, et al. Evidence based physical activity for school-age youth. J. Pediatr. 146:732-737, 2005.

33. Sun. D., A. Huang, A. Koller and G. Kaley. Short-term daily exercise activity enhances endothelial NO synthesis in skeletal muscle arterioles of rats. J. Appl. Physiol. 76:2241-2247, 1994.

34. Tanner. J.M. Growth at Adolescence, 2nd ed. Oxford, UK: Blackwell, 1962.

35. Taylor, W.F., J.M. Johnson, D. O'Leary, and M.K. Park. Effect of high local temperature on reflex cutaneous vasodilation. J. Appl. Physiol. 57:191-196, 1984.

36. Treiber, F., D. Papavassiliou, B. Gutin, et al. Determinants of endothelium-dependent femoral artery vasodilation in youth. Psychosom. Med. 59:376-381, 1997.

37. Treiber, F.A., L. Musante, S. Hartdagan, H. Davis, M. Levy, and W.B. Strong. Validation of a heart rate monitor with children in laboratory and field settings. Med. Sci. Sports Exerc. 21:338-342, 1989.

38. Vissing, S.F., N.H. Secher, and R.G. Victor. Mechanisms of cutaneous vasoconstriction during upright posture. Acta Physiol. Scand. 159:131-138, 1997.

39. Watts, K., P. Beye, A. Siafarikas, et al. Exercise training normalizes vascular dysfunction and improves central adiposity in obese adolescents. J. Am. Coll. Cardiol. 43:1823-1827, 2004.

40. Zinman, B., N. Ruderman, B.N. Campaigne, J.T. Devlin, and S.H. Schneider, American Diabetes Association. Physical activity/exercise and diabetes. Diabetes Care. 27:S58-S62, 2004. 
Copyright of Pediatric Exercise Science is the property of Human Kinetics Publishers. Inc. and its content may not be copied or emailed to multiple sites or posted to a listserv without the copyright holder's express written permission. However, users may print, download, or email articles for individual use. 